\title{
A statistical model for determining zearalenone contamination in rice (Oryza sativa L.) at harvest and its prediction under different climate change scenarios in South Korea
}

\author{
Yongsung Joo', Hyun Ee Ok², Jihyun Kim', Sang Yoo Lee², Su Kyung Jang ${ }^{2}$, Ki Hwan Park² \\ and Hyang Sook Chun ${ }^{2^{*}}$ (D)
}

\begin{abstract}
Mycotoxin contamination of food grains is a food safety hazard, and zearalenone (ZEN) is one such mycotoxin affecting rice grains (Oryza sativa L.). A statistical model for estimating the impacts of climate change on ZEN contamination of rice grains in South Korea was constructed. Observational data on ZEN concentrations in rice grains at harvest and local weather information from 241 rice fields in South Korea were collected. To estimate the impact of weather variables on ZEN concentrations, multiple regression analyses were conducted along with variable selection procedure. The final model included the following variables: average temperature and humidity over the flowering period, daily (between days) change in temperature over the harvest period, degree of milling, and the climate region. On the basis of this regression model, maps showing ZEN contamination were produced for South Korea in the present day, the 2030s, and the 2050s, using the representative concentration pathway (RCP) emission scenarios RCP 2.6, 4.5, and 8.5. The predictive maps project that in the 2030s and 2050s, ZEN contamination in rice grains will increase nationwide, particularly more so on the western side of South Korea. Our research results might be helpful in developing effective control measures against ZEN contamination due to climate change.
\end{abstract}

Keywords: Climate change, Predictive map, Rice, Statistical model, Zearalenone

\section{Introduction}

Contamination of stored food and feed with fungal metabolites known as mycotoxins is unavoidable and at times unpredictable. Therefore, it is a great challenge for food safety control. Over the years, there have been efforts towards minimizing risks posed by mycotoxins by applying food safety systems such as hazard analysis and critical control points and good agricultural practices throughout the food supply chain, but mycotoxin contamination remains a problem [1]. The production of mycotoxins is known to be influenced by the nutritional status of crops, storage conditions, and damage caused by

\footnotetext{
*Correspondence: hschun@cau.ac.kr

${ }^{2}$ Department of Food Science and Technology , Chung-Ang University, Anseong 456-756, South Korea

Full list of author information is available at the end of the article
}

insects or pests, which are affected by climate conditions [2]. Thus, climate is the most important factor affecting fungal colonization and mycotoxin production $[3,4]$.

Among mycotoxins, zearalenone is a nonsteroidal estrogenic mycotoxin biosynthesized via a polyketide pathway by a variety of Fusarium fungi [1]. These fungi include Fusarium graminearum (Gibberella zeae), F. culmorum, F. equiseti, and F. cerealis, which infect preharvest grains. However, fungal growth and ZEN production may also occur after harvest under poor storage conditions [5]. A wide variety of cereals such as barley, oats, wheat, and rice are susceptible to ZEN contamination, both in temperate and warmer climate zones $[1,6]$.

Rice (Oryza sativa L.) is an important grain for half of the world's population, and it provides $27 \%$ of the dietary energy supply and accounts for $20 \%$ of dietary 
protein intake in the developing world [7]. Currently, rice is important as a staple food for the Korean population, the average daily intake of milled rice in Korea being $180.8 \mathrm{~g}$ per person [8]. During the cultivation and subsequent handling of rice, kernels can be contaminated by mainly Fusarium fungi and ZEN mycotoxin if conditions are favorable [9-11]. The occurrence of this toxin in rice grains is reported to be influenced by environmental factors such as temperature, humidity, and the degree of rainfall during the preharvest, harvest, and postharvest periods $[4,12]$.

It is forecast that by 2100 , the global temperature will be $4.8{ }^{\circ} \mathrm{C}$ higher and precipitation $6 \%$ higher if humankind continues to use fossil fuels without mitigating emissions [13, 14]. Meanwhile, the temperature and rainfall in South Korea will increase by up to $4.6{ }^{\circ} \mathrm{C}$ and $0.5 \mathrm{~mm} \mathrm{day}^{-1}$, respectively [15]. These increases in average temperature and precipitation in South Korea are higher than the global average, which will have various impacts on the infection of crops by toxigenic fungi and the resultant mycotoxin contamination.

Several reviews on the impacts of climate change on mycotoxins, including ZEN, have pointed to the need for models to quantify these impacts $[3,16]$. A forecasting system to predict the potential for elevated mycotoxin levels would be useful for harvesting and marketing decisions. The models developed to date have been mainly based on statistical relationships between the presence of specific mycotoxins-such as aflatoxins, deoxynivalenol (DON), and fumonisins-and meteorological and/ or agronomy-related factors $[17,18]$. A model to predict the concentrations of DON in wheat during heading, DONcast, can explain $63-86 \%$ of the variability in DON levels at harvest $[18,19]$. Furthermore, a model that can describe DON and ZEN contamination in maize grown in the Netherlands has been derived [4]. Dowd reported a model predictive of fumonisin and aflatoxin in maize under US corn belt conditions [20]. Temperature, rainfall, and insect presence were the most important variables identified.

To date, no models to predict the occurrence and/or the incidence of ZEN in rice have been reported. The objectives of this study were to build a descriptive model estimating the effects of weather on the contamination of rice with ZEN, and to generate maps of potential ZEN contamination in rice in South Korea under the following representative concentration pathway (RCP) emission (climate change) scenarios: RCP 2.6, 4.5, and 8.5.

\section{Materials and methods}

Collection of rice samples and milling

Freshly harvested paddy rice samples were collected once yearly-from 80 farms in 2010, 80 farms in 2011, and 81 farms in 2012, considering the representativeness of the rice-producing areas and climatic patterns [21]. These farms were located at nine different sites in South Korea, each of which has slightly different field cultivation conditions (Table 1). Geographic coordinates: latitude, 34.5$37.7^{\circ} \mathrm{N}$ and longitude, $126.6-129.3^{\circ} \mathrm{E}$; climatic conditions: annual mean temperature, $12.2-14{ }^{\circ} \mathrm{C}$ and relative humidity (RH), $62-74 \%$. The sites included Gangneung $(n=60)$, Hwaseong $(n=51)$, Anseong $(n=20)$, Jeongeup $(n=30)$, Haenam $(n=10)$, Ulsan $(n=10)$, Uiseong $(\mathrm{n}=20)$, Hamyang $(\mathrm{n}=20)$, and Boseong $(\mathrm{n}=20)$. Paddy rice (about $10 \mathrm{~kg}$ from each farm) was taken from the grain-collecting yard just before it was processed through

Table 1 Weather conditions of the nine locations where rice was harvested in the period of 2010-2013

\begin{tabular}{|c|c|c|c|c|c|c|c|}
\hline \multirow{2}{*}{$\begin{array}{l}\text { Area code } \\
\text { (administrative } \\
\text { district) }\end{array}$} & \multirow[t]{2}{*}{ Climatic zone } & \multicolumn{2}{|c|}{ Geographical coordinates } & \multicolumn{4}{|c|}{ Weather conditions } \\
\hline & & Latitude ( $\left.{ }^{\circ} \mathrm{N}\right)$ & Longitude $\left({ }^{\circ} \mathrm{E}\right)$ & $\mathrm{T}_{\text {flower }}{ }^{\mathrm{a}}\left({ }^{\circ} \mathrm{C}\right)$ & $\mathrm{RH}_{\text {flower }} \mathbf{b}(\%)$ & $\mathrm{TC}_{\text {harvest }}{ }^{\mathrm{c}}\left({ }^{\circ} \mathrm{C}\right)$ & $\mathrm{RHC}_{\text {harvest }} \mathrm{d}(\%)$ \\
\hline A (Gangneung) & I & 37.7 & 128.8 & 27.4 & 71.7 & -0.8 & -7.3 \\
\hline B (Hwaseong) & $\|$ & 37.1 & 126.8 & 26.3 & 79.3 & 1.2 & -4.3 \\
\hline C (Anseong) & $\|$ & 37.0 & 126.8 & 25.6 & 83.9 & 1.8 & -0.3 \\
\hline D (Uiseong) & III & 36.2 & 128.2 & 26.2 & 81.7 & -1.7 & 7.9 \\
\hline$E($ Ulsan $)$ & III & 35.5 & 129.3 & 27.4 & 80.4 & 0.7 & 12.0 \\
\hline F (Joengeup) & III & 35.5 & 126.8 & 27.5 & 80.1 & 1.0 & 10.4 \\
\hline G (Hamyang) & III & 35.3 & 127.4 & 25.3 & 90.1 & -2.8 & 5.9 \\
\hline H (Heanam) & III & 34.5 & 126.6 & 27.9 & 87.2 & -1.2 & 5.8 \\
\hline I (Boseong) & III & 34.4 & 127.1 & 26.9 & 85.4 & 1.0 & -3.8 \\
\hline
\end{tabular}

\footnotetext{
a Average temperature over the flowering period

b Average relative humidity over the flowering period

c Average daily temperature change over the harvest period

d Average daily relative humidity change over the harvest period
} 
a rice-processing complex (an integrated rice postharvest facility) at harvest time (September-October). Before milling, paddy samples (27-33\% moisture content) were air dried at room temperature $\left(20-25{ }^{\circ} \mathrm{C}\right.$, $\left.\mathrm{RH} 40-50 \%\right)$ for $48 \mathrm{~h}$. The hulls were removed from the dried paddy rice $(19 \% \pm 2 \%$ moisture content) using a mill (Model HSMC-4; Hansung Industrial Co., Ltd., Yesan, Korea), and the sample was fractionated by paddy rice weight into $24 \%$ hulls and $76 \%$ brown rice. White rice $(76 \%$ of brown rice weight) was obtained by milling brown rice using a commercial grinder (Model: Yamaha, Yamamoto, VT-21T, Yamagata, Japan). These milling fractions were stored at $0-3{ }^{\circ} \mathrm{C}$ until their use for analysis. All samples were pulverized using a blender until they could pass through a No. 20 sieve. Samples were stored at $-18{ }^{\circ} \mathrm{C}$ in an aluminum zipper bag (approximately $250 \mathrm{~g}$ ) until analysis.

\section{ZEN analysis}

ZEN analysis was performed using a method adapted by Ok et al. [11].

Ground sample (25 g) was weighed and placed in a $200 \mathrm{~mL}$ beaker containing $100 \mathrm{~mL}$ of extraction solvent (acetonitrile:distilled water $=75: 25, \mathrm{v} / \mathrm{v}$ ), $2 \mathrm{~g}$ of sodium chloride, and $1 \mathrm{~mL}$ of Tween 20 . The mixture was homogenized for 3 min using an Ultra Turrax homogenizer (Staufen, Germany) and then filtered through Whatman No. 1 filter paper (Maidstone, UK).

Ten milliliters of filtrate was diluted with $40 \mathrm{~mL}$ of distilled water and then filtered through a GF/B glass microfiber filter paper. Twenty-five milliliters of the filtrate was loaded on immunoaffinity columns (IAC; ZearalaTest WB, Vicam, Milford, MA, USA). After all the filtrate was eluted through the IAC by gravity, the IAC was then washed with $20 \mathrm{~mL}$ of distilled water. The water remaining in the IAC was removed by passing air using a syringe. Finally, ZEN was eluted from the IAC using $3 \mathrm{~mL}$ of methanol. The resulting eluate was dried at $50{ }^{\circ} \mathrm{C}$ with a water bath and then reconstituted with $1 \mathrm{~mL}$ of the mobile phase solution (acetonitrile:water:methanol $=10$ : $35: 5, \mathrm{v} / \mathrm{v} / \mathrm{v})$. After filtration with a $0.2 \mu \mathrm{m}$ PVDF syringe filter, $20 \mu \mathrm{L}$ of this solution was injected into a highpressure liquid chromatography (HPLC) column (Synergi Hydro-RP, $250 \times 4.6 \mathrm{~mm}, 4 \mu \mathrm{m}$; Phenomenex, Inc., Torrance, CA, USA). The flow rate of the mobile phase was

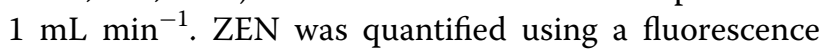
detector (excitation at $275 \mathrm{~nm}$ and emission at $450 \mathrm{~nm}$ ).

\section{In-house validation}

The method of detecting ZEN in rice hulls, white rice, and brown rice using HPLC was validated using in-house methods [22]. The linearity was assessed from the calibration curve in terms of coefficient of determination $\left(R^{2}\right)$.
Recovery and repeatability were calculated by repeating the experiment five times with three rice samples (rice hulls, white rice, and brown rice) spiked with four different levels of ZEN (50, 100, 200, and $500 \mathrm{mg} \mathrm{kg}^{-1}$ ). The limit of detection (LOD) and limit of quantification (LOQ) were calculated by the formula using the slope of the calibration curve and the standard deviation of the response $(\mathrm{LOD}=3.3 \times \sigma / \mathrm{S}, \mathrm{LOQ}=10 \times \sigma / \mathrm{S}, \sigma$ : standard deviation of the response, $\mathrm{S}$ : slope of the calibration curve). The linearity of the method showed $R^{2} \geq 0.999$ in the range analyzed. The LOD and LOQ of the method were $4 \mu \mathrm{g} \mathrm{kg}^{-1}$ and $13 \mu \mathrm{g} \mathrm{kg}^{-1}$, respectively. The recovery was $86-115 \%$, and the repeatability (expressed as the relative standard deviation) was $4.3-12.8 \%$. All analytical procedures (extraction, cleanup, and HPLC analysis) fulfilled the criteria of the European Commission specifications [23].

\section{Weather data on field}

Data for the average temperature and $\mathrm{RH}$ were collected over the present (2004-2013) and future flowering and heading periods of rice from the Korean Metrological Administration (https://web.kma.go.kr/eng/index.jsp). Future weather data were obtained based on RCP 2.6, 4.6 , and 8.5 emission scenarios [13, 14]. Four meteorological variables were then generated. Average temperature $\left(\mathrm{T}_{\text {flower }}\right)$ and $\mathrm{RH}\left(\mathrm{RH}_{\text {flower }}\right)$ were calculated over the flowering period. Daily temperature $\left(\mathrm{TC}_{\text {harvest }}\right)$ and $\mathrm{RH}$ $\left(\mathrm{RHC}_{\text {harvest }}\right)$ changes were calculated over a week of the harvest period, obtained by summing the temperature or RH drop compared to the previous day over a 7-day period prior to the harvest date.

\section{Model development}

ZEN concentration measurement data typically required two preprocesses before common statistical methods were applied. First, because the distribution of data is positively skewed and above zero, $\log _{\mathrm{e}}$ or $\log _{10}$ transformation is often used to make it normal or close to normal distribution for further statistical analysis. For example, the regression model requires the response variable, given the explanatory variable has normal distribution. In this study, we used $\log _{10}$ transformation. Second, ZEN concentration measurement had a LOD of $4 \mu \mathrm{g} \mathrm{kg}$. Observations below the detection limit are called "nondetectable" (ND) or "censored data." In this study, 1 out of 239 rice hull samples, 70 out of 241 brown rice samples, and 223 out of 241 white rice samples were ND. Because common statistical techniques assume all observations are measured without any detection limit, some datahandling processes were necessary before applying these statistical methods to the ZEN data. 
A common and the simplest preprocess is replacing ND with LOD/2 or LOD. Because $\log _{\mathrm{e}}$ or $\log _{10}$ transformation is often applied after the replacement, ND cannot be replaced with 0 . However, the choice of a replacement value can be subjective and cause biases to the results of further statistical analyses, such as regression analysis. Therefore, the replacement preprocess is not a satisfactory solution and should be avoided, if possible.

To overcome this problem, a few statistical methods have been developed that do not require the replacement preprocess [24]. The expectation-maximization algorithm was utilized in estimating the distribution of a data set with ND observations [25]. A censored regression method was developed for the regression analysis of data sets with ND observations [24].

In this study, to build a prediction model for the ZEN measurements with a detection limit, we performed censored regression analysis. The "censReg" package in $\mathrm{R}$ software [26] was used. As predictors, we used four weather variables; two sets of dummy variables to indicate the degree of milling; and three climate regions, into which Park et al. divide South Korea based on rainfall and air temperature patterns [21].

\section{Predicted spatial map}

The selected model was used to estimate changes in ZEN contamination in mature rice throughout South Korea under specific climate change scenarios for the 2030s and 2050s. The scenarios selected were the RCP 2.6, 4.5, and 8.5 emissions used in the fifth evaluation report of the Intergovernmental Panel on Climate Change (IPCC) $[13,14]$. The three RCPs, namely RCP 2.6 , RCP 4.5 , and RCP 8.5 , are labeled after possible ranges of radiative forcing values in the year $2100\left(2.6,4.5\right.$, and $8.5 \mathrm{~W} \mathrm{~m}^{-2}$, respectively). The RCPs represent a wide range of possible changes in future anthropogenic greenhouse gas emissions. The best-case scenario RCP 2.6 assumes that global annual greenhouse gas emissions peak between 2010 and 2020, but decline substantially thereafter. Emissions in RCP 4.5 peak around 2040, and then decline. In the worst-case scenario RCP 8.5, emissions continue to rise throughout the twenty-first century $[13,14]$. The variables, such as temperature and $\mathrm{RH}$ over the flowering and harvest periods from the Korea Meteorological Administration (https://www.kma.go.kr), were used to obtain the predicted spatial distribution of ZEN contamination from 2030 to 2039 and from 2050 to 2059.

\section{Results}

\section{Concentration of ZEN in rice grains at harvest}

The box plot of the ZEN concentrations in rice hulls, brown rice, and white rice are shown in Fig. 1. For ND, we took the $\log (\mathrm{LOD} / 2)$ to plot on the $\log$ scale. The

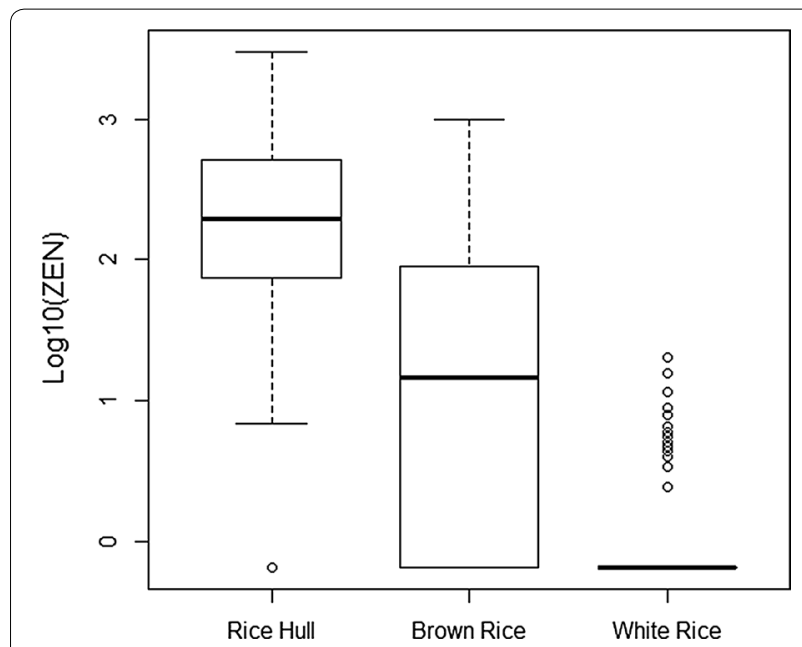

Fig. 1 ZEN concentrations (log-transformed, $\mu \mathrm{g} \mathrm{kg}^{-1}$ ) in rice hulls, brown rice, and white rice collected in 2010-2012: box plots mark the Q3 (75 percentile) of $\log 10$ (ZEN) with upper boundary of a box, the median (50 percentile) with middle line, the Q1 (25 percentile) with lower boundary, and potential outliers (1.5 times of interquartile range away from Q1 or Q3) with circles

median values of ZEN concentrations in rice hulls, brown rice, and white rice, which differed in the degree of milling, were $194.8 \mu \mathrm{g} \mathrm{kg}^{-1}, 14.5 \mu \mathrm{g} \mathrm{kg}^{-1}$, and $0.01 \mu \mathrm{g} \mathrm{kg}^{-1}$, respectively. As in an earlier study, because the distribution of ZEN concentrations was skewed in the original scale (without using the log scale), medians were used to explain the central tendency of ZEN concentrations instead of averages [27]. Figure 2a shows the geographical distribution of ZEN contamination in rice hulls based on the median of observations at each sampling site. In general, ZEN concentration was higher in the western part (C, F, and $\mathrm{H}$ regions) of South Korea than in other parts (D and $G$ regions).

\section{Factors affecting the level of ZEN in rice grains at harvest}

A censored regression analysis was conducted with the whole data set. Then, significant variables were selected using a "stepwise selection" method to control multicollinearity among predictors [28]. When the $p$-value was $<0.05$, a variable was considered a significant predictor. Coefficient estimates of significant predictors are presented in Table 2. REGION1 and 2 indicate the eastern and western parts of South Korea, respectively [21]. BROWN and WHITE are dummy variables for brown rice and white rice. In constructing dummy variable sets, REGION3 (the southern part of South Korea) and rice hulls were used as references. Note that "N/A" means that the corresponding variables were not selected in the regression model. The results in Table 2 are summarized in Eq. (1). 

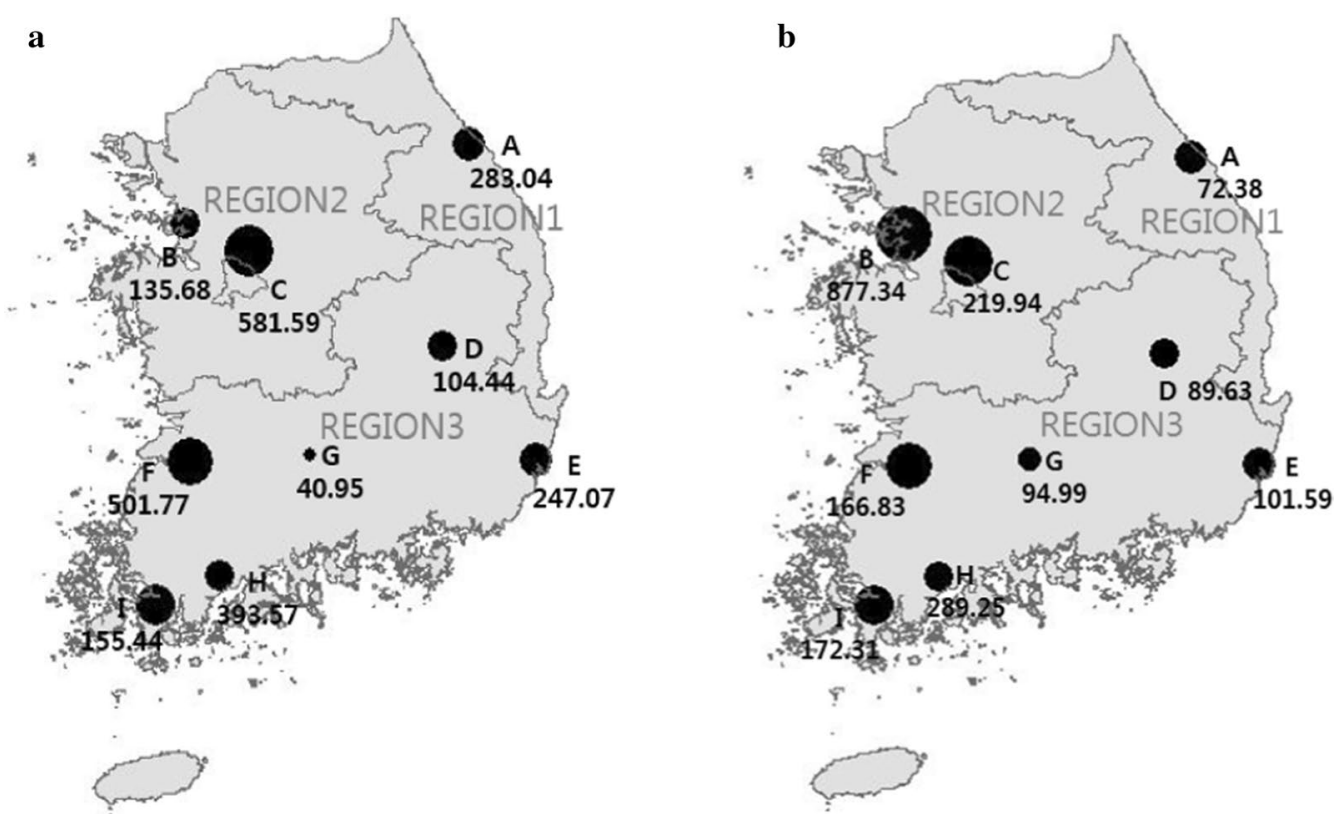

Fig. 2 Medians of ZEN concentrations in rice hulls: a observed and $\mathbf{b}$ estimated: the ball sizes are proportional to the median concentration $\left(\mu \mathrm{kg}^{-1}\right)$ of ZEN

Table 2 Parameter estimates in the censored regression model with ZEN in rice as the response variable

\begin{tabular}{lll}
\hline Variable & \multicolumn{2}{l}{ Parameter estimates } \\
\cline { 2 - 3 } & Coefficient & p-value \\
\hline Intercept & -17.593 & $<10^{-5}$ \\
REGION1 & $\mathrm{N} / \mathrm{A}^{\mathrm{a}}$ & - \\
REGION2 & 0.672 & $<10^{-5}$ \\
BROWN & -1.233 & $<10$ \\
WHITE & -3.311 & $<10$ \\
$T_{\text {flower }}$ & 0.535 & $<10$ \\
$R H_{\text {flower }}$ & 0.058 & $<10$ \\
$T C_{\text {harvest }}$ & 0.457 & $<10$ \\
$R H C_{\text {harvest }}$ & $\mathrm{N} / \mathrm{A}$ & - \\
\hline
\end{tabular}

a The variables with $\mathrm{N} / \mathrm{A}$ are those eliminated from the stepwise selection process with the selection criteria $(p=0.05)$

$$
\begin{aligned}
\log _{10}\left(\text { Zearalenone }_{\text {rice }}\right)= & -17.593+0.672 \times \text { REGION2 } \\
& -1.233 \times \mathrm{BROWN}-3.311 \\
& \times \mathrm{WHITE}+0.535 \\
& \times T_{\text {flower }}+0.058 \times \mathrm{RH}_{\text {flower }} \\
& +0.457 \times T C_{\text {harvest }}
\end{aligned}
$$

The negative coefficients of BROWN and WHITE indicate that brown rice and white rice have $94.1 \%$ $\left(=1-10^{-1.233}\right)$ and $99.9 \%\left(=1-10^{-3.313}\right)$ less ZEN than that of rice hulls, respectively.
The significantly positive coefficients of the $T_{\text {flower }}$ and $R H_{\text {flower }}$ hulls can be interpreted as follows: as the average temperature increases, the environmental conditions for fungal growth improve, and hence, fungal numbers increase, resulting in increased production of mycotoxin until the harvest date. Figure $2 \mathrm{~b}$ shows the estimated median ZEN concentrations in rice hulls based on the weather data of 2010-2012 using Eq. (1). The estimated ZEN concentrations in Fig. $2 \mathrm{~b}$ are close to the observed ZEN concentrations in Fig. 2a, which shows that the prediction model fits the data well.

\section{Future prediction of ZEN levels in rice grains on the basis of RCP 2.6, 4.5, and 8.5 scenarios}

We constructed prediction maps of ZEN contamination in rice hulls based on the future weather data of the 2030s and 2050s from the RCP2.6, 4.5, and 8.5 emission scenarios, as well as a prediction map based on recently observed weather data for the period 2004-2013. On the basis of Eq. (1) and the above information, we predicted an increase in the average ZEN concentrations, as shown in Fig. 2b. Predictive maps showed that the ZEN contamination in rice is expected to increase nationwide, and particularly more so on the western side of South Korea in the 2030s and 2050s. Increased contamination with ZEN is predicted under all climate change scenarios. Hence, ZEN contamination is projected to increase, particularly in the western and southern areas of this country (Fig. 3). 


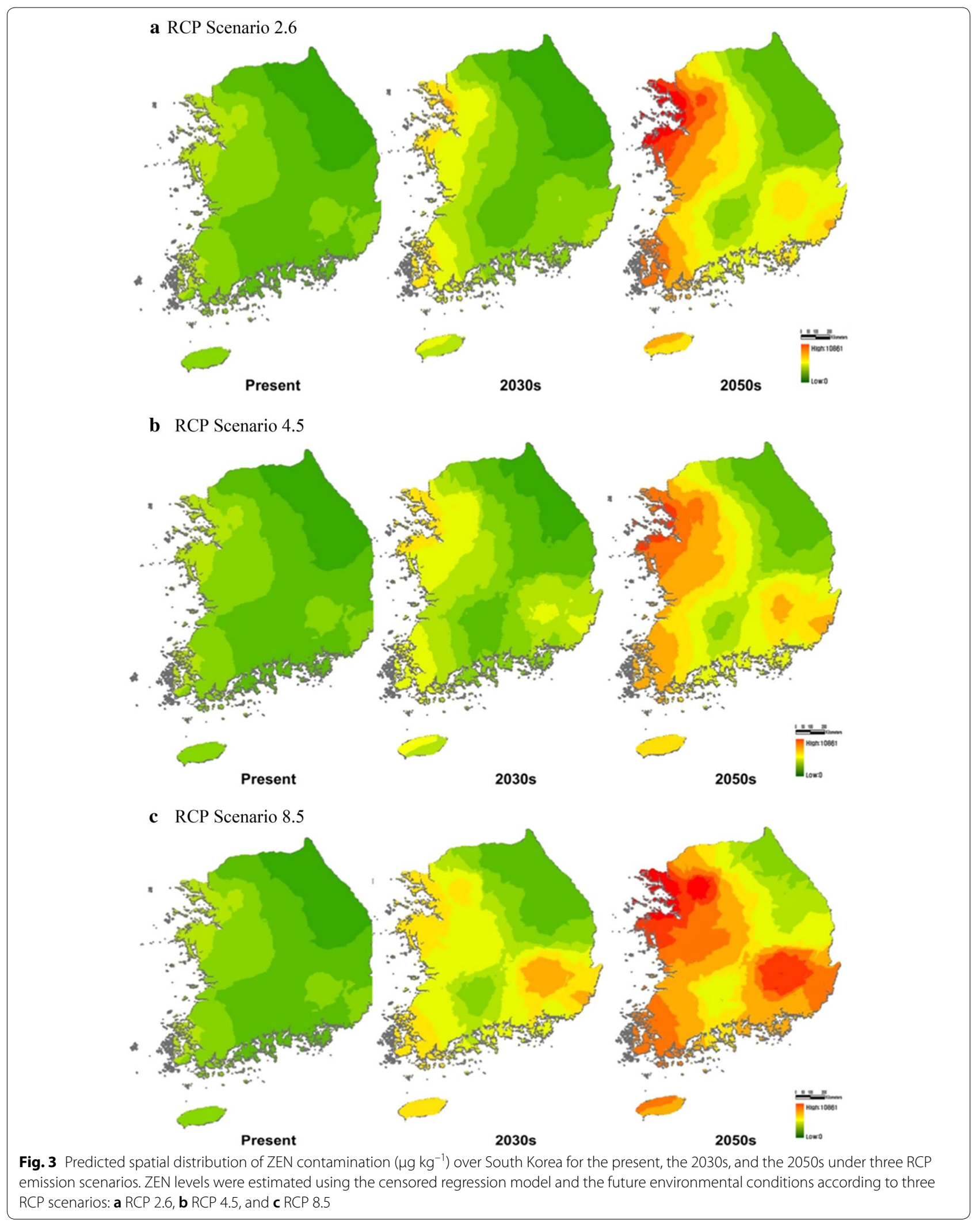




\section{Discussion}

In the present study, a descriptive model for the prediction of ZEN contamination of rice grains at harvest in South Korea was developed using ZEN concentration data in rice milling fractions. Furthermore, future predictions for ZEN contamination were illustrated under three possible scenarios of climate change.

ZEN analysis was performed on 241 rice samples collected from nine different locations in South Korea during the period 2010-2012. As expected, the ZEN content was the highest (range $0.4-95.4 \mathrm{\mu g} \mathrm{kg}^{-1}$ ) in the hull, followed by brown rice and white rice. These results suggest that the level of ZEN is reduced by the milling process [29]. Natural contamination levels of ZEN in the hull, brown rice, and white rice seemed to be related to the geographic location. A high level of ZEN was found in rice samples collected from the western part of South Korea $\left(\mathrm{C}\right.$ and $\left.\mathrm{F}, 126.8^{\circ} \mathrm{E}\right)$, where the $\mathrm{RH}_{\text {flower }}$ and $\mathrm{TC}_{\text {harvest }}$ are relatively high.

The ZEN content in Korean brown rice in this period (average of $14 \mu \mathrm{g} \mathrm{kg}^{-1}$, maximum of $201 \mu \mathrm{g} \mathrm{kg}^{-1}$ ) was in the same order of magnitude as the ZEN content in rice reported for the year 2007 (average of $96 \mu \mathrm{g} \mathrm{kg}^{-1}$, maximum of $235 \mu \mathrm{g} \mathrm{kg}^{-1}$ ) [10]. These levels are considerably higher than the levels reported for rice samples collected in 2002 (average of $2.8 \mu \mathrm{g} \mathrm{kg}^{-1}$ for the southern region, average of $3.9 \mathrm{\mu g} \mathrm{kg}^{-1}$ for the northern region) [12]. This might be due to more favorable climatic conditions or other factors, such as changes in land use, resulting in higher environmental infection pressure or changing fungal populations. We have demonstrated earlier that the levels of $F$. graminearum are primarily responsible for the ZEN levels in Korean rice [11].

In this study, a descriptive model estimating the effects of weather variables on the ZEN contamination of rice was generated by a censored regression analysis. The regression model included the following variables: average temperature and humidity over the flowering period, daily (between days) change in temperature over the harvest period, degree of milling, and climate region. Variables in the selected model were comparable to those in published models, including $\mathrm{RH}$ and temperature during critical stages of crop cultivation $[17-19,30]$. The results indicated that increased temperature and $\mathrm{RH}$ during rice cultivation, particularly over the period around rice heading, and changes in daily temperature over the harvest period increased ZEN concentrations at rice harvest. F. graminearum was the dominant ZEN-producing Fusarium species in the region during the time frame of the current study $[10,11,31]$. The significantly positive coefficients of $T_{\text {flower }}$ and $R H_{\text {flower }}$ can be interpreted as follows: over the flowering period, as the average temperature increased, environmental conditions for the growth of fungi such as F. graminearum improved, and hence, the number of fungi increased, resulting in an increased production of ZEN until the harvest date. In addition, a change in the daily temperature over the harvest period has been found to positively influence the ZEN concentrations, in agreement with the results of Sherwood and Peberdy [32].

To our knowledge, the current regression model is the first attempt to quantify ZEN levels in rice based on weather parameters, even though the nine sampling sites were narrow and the study period 2010-2013 for ZEN data was not adequate to reflect environmental perspectives, such as nutrient bioavailability and insect damage. Therefore, although the model provided a good estimation of the observed trends in ZEN levels, further external validation is required, which may reveal that agronomic factors, such as previous crops cultivated and previous tillage practices, need to be included in the model. These factors have been shown to influence mycotoxin levels in rice, as they were related to the fungal levels present in the field at the start of the planting season [33]. However, the inclusion of such factors in the model should be carefully considered because they might complicate the model [4]. Nevertheless, the current model, without the agronomic factors mentioned, is capable of describing trends in ZEN levels over the years. However, our model can give only rough estimates of ZEN levels in rice based on weather parameters.

Although there is no model that predicts the relationship between ZEN levels in rice and climate change, a number of predictive models have been developed worldwide, such as for Fusarium head blight and the risk of DON contamination in wheat and maize grains $[18,19$, 30, 34]. The well-known prediction model, DONcast, is based on the weather conditions just before and during wheat head emergence [19]. It includes the input of local or regional weather data, namely, the number of rain days just before and after anthesis and during ripening, and the maximum, minimum, and mean temperatures. Recently, van Asselt et al. reported a mixed empiricmechanistic model that describes fungal infection during silking (based on wind speed and rainfall) and subsequent germination, growth, and toxin (DON and ZEN) formation, depending on temperature and water availability in maize [4]. They also suggest that the derived model can give only rough estimates of DON and ZEN levels in maize based on weather parameters.

The IPCC has provided RCP 2.6, 4.5, 6.0, and 8.5 scenarios with projected future climate conditions based on different socioeconomic scenarios [14]. While RCP 8.5 is the worst among the four scenarios, assuming high population and high greenhouse gas emission over 
time by 2100 , RCP 2.6 is the best, assuming low population and very low greenhouse gas emission. The predicted spatial distribution of ZEN levels in rice grains is presented here based on the future weather data in the 2030s and 2050s from the RCP 2.6, 4.5, and 8.5 emission scenarios, as well as a prediction map based on recently observed weather data in the 2004-2013 period.

Predictive maps showed a nationwide increase in ZEN contamination, particularly more on the western side of South Korea in the 2030s and 2050s through all climate change scenarios. This can be explained, at least partially, by the higher $\mathrm{TC}_{\text {harvest }}$ values in these areas than those in other areas. At a higher $\mathrm{TC}_{\text {harvest }}$, favorable conditions for fungal growth and ZEN formation were generated, and hence, the number of fungi increased, thereby increasing ZEN levels at the harvest date. As expected, the levels of ZEN contamination increased in the order of RCP 2.6, 4.5, and 8.5. It is predicted that ZEN contamination will shift upwards, and the levels in the western and southern areas will increase more.

However, our future ZEN predictions are beset with uncertainties. First, because we chose to use weather conditions projected in RCP 2.6, 4.5, and 8.5 scenarios, uncertainties associated with these scenarios carried over into ZEN predictions. Second, as with any other statistical model, our censored regression model has its own uncertainties. Third, our model is an empirical model, which provides little insight into the cause-andeffect relationships and interactions among the variables. Fourth, our model is based on limited ZEN data with a relatively short period and a narrow geographical range; it cannot be applied to other geographic areas without proper model testing.

ZEN is a heat-stable estrogenic mycotoxin produced before harvest and, to a lesser extent, during the storage of the rice crop. Thus, attention should be paid to preventing hazards associated with ZEN from the viewpoint of public health and food hygiene. Our results could be used by controlling authorities to develop effective control measures against future ZEN contamination due to climate change. However, the prediction of the impact of climate change on ZEN remains fraught with the aforementioned limitations. Furthermore, there is little understanding of how the interaction between abiotic and biotic factors, including insect damage, affects ZEN production. Therefore, further research is required to improve the predictive model based on different climate change scenarios and long-term datasets for ZEN and ZEN-producing fungi.

\section{Acknowledgements}

We also thank Dr. Jihyun Song for her assistance with writing a part of this manuscript.

\section{Authors' contributions}

YS and JH performed statistical analyses. HE, SY and SK analyzed the zearalenone content in the samples. YS and HS interpreted the observed data. KH and $\mathrm{HS}$ supervised the project. HS designed the experiments. HS and SY wrote the manuscript in consultation with $\mathrm{YS}, \mathrm{HE}, \mathrm{JH}$, and $\mathrm{KH}$. All authors read and approved the final manuscript.

\section{Funding}

This research was supported by a Grant (10162KFDA995) from the Korea Food and Drug Administration, and was supported by the Chung-Ang University Graduate Research Scholarship.

\section{Availability of data and materials}

The datasets used and/or analyzed during the current study are available from the corresponding author on reasonable request.

\section{Competing interests}

The authors declare that they have no competing interests.

\section{Author details}

${ }^{1}$ Department of Statistics, Dongguk University-Seoul, Pil-dong 3-ga, Jung-gu, Seoul, South Korea. ${ }^{2}$ Department of Food Science and Technology, ChungAng University, Anseong 456-756, South Korea.

Received: 11 March 2019 Accepted: 17 July 2019

Published online: 26 July 2019

\section{References}

1. EFSA Panel on Contaminants in the Food Chain (2011) Scientific opinion on the risks for public health related to the presence of zearalenone in food. EFSA J 9:2197-2321

2. Paterson RPM, Lima N (2010) How will climate change affect mycotoxins in food? Food Res Int 43:1902-1914

3. Magan N, Medina A, Aldred D (2011) Possible climate-change effects on mycotoxin contamination of food crops pre- and postharvest. Plant Pathol 60:150-163

4. van Asselt ED, Booij CJH, van der Fels-Klerx HJ (2012) Modelling mycotoxin formation by Fusarium graminearum in maize in The Netherlands. Food Addit Contam A 29:1572-1580

5. Bottalico A, Perrone G (2002) Toxigenic Fusarium species and mycotoxins associated with head blight in small-grain cereals in Europe. Eur J Plant Pathol 108:611-624

6. Bennett JW, Klich M (2003) Mycotoxins. Clin Microbiol Rev 16:497-516

7. Food and Agriculture Organization of the United Nations (FAO) (2004) Rice is life: international year of rice 2004. https://www.fao.org/rice2004/ en/rice2.htm. Accessed 19 Mar 2018

8. Korean Ministry of Health and Welfare (KMHW) (2009) The Korean national health and nutrition examination survey (KNHANES IV) 2008 nutrition survey IV. Korean Ministry of Health and Welfare, Seoul

9. Karunakara Murthy K, Rati ER, Manonmani HK (2009) Incidence of Fusarium toxins in rice from Karnataka, India. Res J Toxins 1:1-7

10. Lee T, Lee SH, Lee SH, Shin JY, Yun JC, Lee YW, Ryu JG (2011) Occurrence of Fusarium mycotoxins in rice and its milling by-products in Korea. J Food Prot 74:1169-1174

11. Ok HE, Kim DM, Kim D, Chung SH, Chung MS, Park KH, Chun HS (2014) Mycobiota and natural occurrence of aflatoxin, deoxynivalenol, nivalenol and zearalenone in rice freshly harvested in South Korea. Food Control 37:284-291

12. Park JW, Choi SY, Hwang HJ, Kim YB (2005) Fungal mycoflora and mycotoxins in Korean polished rice destined for humans. Int J Food Micobiol 103:305-314

13. Field CB, Barros VR, Dokken DJ, Mach KJ, Mastrandrea MD, Bilir TE, Chatterjee M, Ebi KL, Estrada YO, Genova RC, Girma B, Kissel ES, Levy AN, MacCracken S, Mastrandrea PR, White LL (2014) IPCC, 2014: climate change 2014: impacts, adaptation, and vulnerability. Part A: global and sectoral aspects. Contribution of working group II to the Fifth Assessment Report of the Intergovernmental Panel on Climate Change. Cambridge University Press, Cambridge 
14. Stocker TF, Qin D, Plattner GK, Tignor MMB, Allen SK, Boschung J (eds) (2013) Climate change 2013: the physical science basis, working group I contribution to the Fifth Assessment Report of the Intergovernmental Panel on Climate Change. Cambridge University Press, Cambridge

15. Ahn J, Choi Y, Jo S, Hong J (2014) Projection of 21st century climate over Korean Peninsula: temperature and precipitation simulated by WRFV3.4 based on RCP4.5 and 8.5 scenarios. J Korean Meteor Soc 24:541-554

16. Paterson RPM, Lima N (2011) Further mycotoxin effects from climate change. Food Res Int 44:2555-2566

17. Hooker DC, Schaafsma AW, Tamburic-llincic L (2002) Using weather variables pre- and post-heading to predict deoxynivalenol content in winter wheat. Plant Dis 86:611-619

18. Schaafsma AW, Hooker DC (2007) Climatic models to predict occurrence of Fusarium toxins in wheat and maize. Int J Food Microbiol 119:116-125

19. Hooker DC, Schaafsma AW (2003) The DONcast model: using weather variables pre- and post-heading to predict deoxynivalenol content in winter wheat. Asp Appl Biol 68:117-122

20. Dowd PF (2003) Insect management to facilitate preharvest mycotoxin management. J Toxicol Toxin Rev 22:327-350

21. Park C, Choi Y, Moon JY, Yun WT (2009) Classification of climate zones in South Korea considering both air temperature and rainfall. J Korean Chem. Soc 44:1-16

22. International Union of Pure and Applied Chemistry (IUPAC) (2002) Harmonized guidelines for single-laboratory validation of methods of analysis (IUPAC Technical Report). Pure Appl Chem 74:835-855

23. European Commission (EC) (2006) Commission Regulation (EC) No. 401/2006 of 23 February 2006 laying down the methods of sampling and analysis for the official control of the levels of mycotoxins in foodstuffs. OJ L 70:12-34

24. Bruno G (2004) Limited dependent panel data models: a comparative analysis of classical and Bayesian inference among econometric packages. In: Computing in economics and finance, vol 41.
25. Casella G, Robert C (2004) Monte Carlo statistical methods, 2nd edn. Springer, Ithaca

26. Henningsen A (2011) censReg: Censored regression (tobit) models. R package version 0.5. https://CRAN.R-project.org/package=censReg. Accessed 15 Jan 2018

27. Triola MF (2012) Elementary statistics, 4th edn. Pearson, Boston

28. Kutner MH, Nachtsheim CH, Neter J, Li W (2005) Applied linear statistical models, 5th edn. McGraw-Hill, Boston

29. Trucksess MW, Abbas HK, Weaver CM, Shier WT (2007) Distribution of aflatoxins in shelling and milling fractions of naturally contaminated rice. Food Addit Contam A 28:1076-1082

30. Battilani P, Rossi V, Pietri A (2003) Modelling Fusarium verticillioides infection and fumonisin synthesis in maize ears. Asp Appl Biol 68:91-100

31. Lee J, Chang IY, Kim H, Yun SH, Leslie JF, Lee YW (2009) Genetic diversity and fitness of Fusarium graminearum populations from rice in Korea. Appl Environ Microbiol 75:3289-3295

32. Sherwood RF, Peberdy JF (1974) Production of the mycotoxin, zearalenone, by Fusarium graminearum growing on stored grain. I. Grain storage at reduced temperatures. J Sci Food Agric 25:1081-1087

33. Lauren DR, Smith WA, Menna MED (2007) Influence of harvest date and hybrid on the mycotoxin content of maize (Zea mays) grain grown in New Zealand. N Z J Crop Hortic Sci 35:331-340

34. de la Campa R, Hooker DC, Miller JD, Schaafsma AW, Hammond BG (2005) Modeling effects of environment, insect damage, and Bt genotypes on fumonisin accumulation in maize in Argentina and the Philippines. Mycopathologia 159:539-552

\section{Publisher's Note}

Springer Nature remains neutral with regard to jurisdictional claims in published maps and institutional affiliations.

\section{Submit your manuscript to a SpringerOpen ${ }^{\circ}$ journal and benefit from:}

- Convenient online submission

- Rigorous peer review

- Open access: articles freely available online

- High visibility within the field

- Retaining the copyright to your article

Submit your next manuscript at $\boldsymbol{\nabla}$ springeropen.com 